\title{
Tributo a Eladio Dieste
}

Algo me queda de mis comienzos periodísticos, oficio que me ha llevado, por intuición, a abrir la página 15 del libro: Eladio Dieste. Innovation in Structural Art editado por la universidad de Princeton.

"Eladio Dieste Saint Martin was born on December 10, 1917, in Artigas, a town in northern Uruguay on the Brazilian border"

¡Bingo! Aún conservo, al menos, el olfato. El año que entra se cumplen cien años del nacimiento de este arquitecto. Curioso nombre el de la ciudad de su nacimiento. Nombre que abordaremos cuando lleguemos a Brasil para hablar de otro gran maestro. Pero esa es otra historia.

La primera vez que llegué a Montevideo solo pude visitar la iglesia de la Atlántida (1958-1960), el almacén del puerto (1977-1979) y el Silo de sal de Solsire (1992-1994). En ese orden. Durante el recorrido se puede apreciar la aparición paulatina de lo esencial en la carrera de este ingeniero que, paradójicamente, cuanto menos arquitecto quiso ser, mejor arquitecto llegó a ser.

Extraigo unos fragmentos de las comunicaciones esclarecedoras con Emilio Nisivoccia. Con su permiso.

\section{Estimado Emilio:}

Quiero agradecerte infinito el texto que nos has regalado. Realmente es lo que estábamos buscando y se ajusta a la calidad que Felipe nos dijo que tenían tus textos.

Me ha parecido especialmente interesante y ayudará a seguir elevando el nivel de rita

Me interesa especialmente la frase que rescato de tu texto:

"El segundo rasgo que marca a fuego la cultura arquitectónica en Uruguay es una marcada vocación por entender la disciplina, mucho más cercana al arte cívico que a una colección de objetos excepcionales"

Gracias por esta extraordinaria aportación y espero que el ejemplar en papel te llegue pronto.

Un abrazo

Arturo

Muchas gracias Arturo, agradezco tus palabras.

Si en algún momento vienes por Montevideo, me gustaría que vieras la cantidad de arquitectura casi anónima, buena y sin demasiadas pretensiones de originalidad que hay en la ciudad. En la primera década de los cuarenta cuando Francis Violich hizo el tour por América Latina escribió que la Facultad de Arquitectura de Montevideo era la mejor de Sudamérica y, claro, a Violich le interesaba la construcción de ciudades y viviendas como soporte para las democracias y por eso se sintió muy a gusto.

Un abrazo.

Emilio.

Hola de nuevo:

Espero volver pronto a Montevideo. Me ha sorprendido muchísimo que, hablando con Felipe y ahora leyendo tu texto, la figura de Dieste ni se nombre. Tal vez haga alusión a algo de esto en el editorial. ¿Qué te parece? Es algo que me llama mucho la atención teniendo en cuenta que Eladio Dieste es casi la única referencia que se tiene de Uruguay desde España en términos generales y sabiendo la influencia que tuvo sobre Solano al que sí citas.

No sé... ¿Cuál es tu opinión?

Un abrazo

Arturo 
Sí, es verdad y también es cierto que Dieste no dejó escuela en Uruguay. Tampoco tengo claro por qué, si por ingeniero, por personalidad, por hacer "galpones" -eso decía él- o por qué cosa, pero el material de Dieste nunca se lo apropiaron con soltura los arquitectos hasta que llegó Benítez que, además, lo utiliza con una libertad envidiable. En Argentina tengo idea que sí hubo algunos "diestianos" aunque sin demasiada gloria.

De hecho, las referencias entre los arquitectos uruguayos pasan por Vilamajó, Payssé Reyes, Sichero, Bayardo, etc. y no por Dieste, que es una especie de figura distante, querido, idolatrado, incluso estudiado, pero siempre manteniendo la distancia. Por ahí pesa demasiado el mito y si alguien lo toma prestado queda como una mala copia.

Es el trauma del "maracanazo": nunca más.

Abrazo.

Emilio.

\section{Arturo Franco}

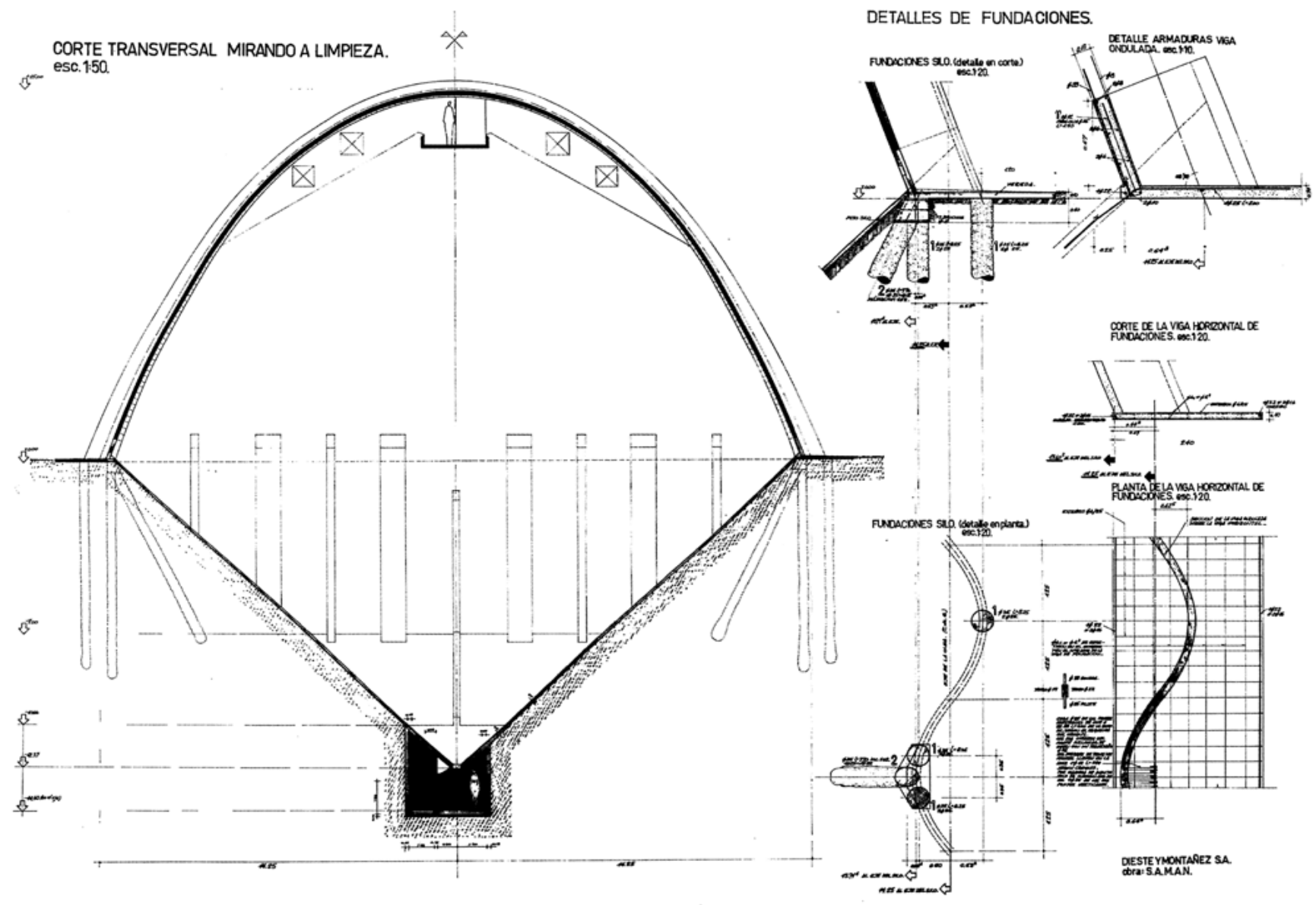

fig. 124

Corte transversal y detalles de

fundaciones. Anderson, Stanford

(Editor). Eladio Dieste. Innovation in

Structural Art. New York: Princeton

Architectural Press, 2004. p.110. 